\title{
Group-based activities with on-site childcare and online support improve glucose tolerance in women within 5 years of gestational diabetes pregnancy
}

Anne-Sophie Brazeau ${ }^{\dagger}$, Aaron Leong ${ }^{\dagger}$, Sara J Meltzer, Rani Cruz, Deborah DaCosta, Mary Hendrickson-Nelson, Lawrence Joseph, Kaberi Dasgupta ${ }^{*}$ and MoMM study group

\begin{abstract}
Background: Women with gestational diabetes history are at increased risk for type 2 diabetes. They face specific challenges for behavioural changes, including childcare responsibilities. The aim of this study is to test a tailored type 2 diabetes prevention intervention in women within 5 years of a pregnancy with gestational diabetes, in terms of effects on weight and cardiometabolic risk factors.

Methods: The 13-week intervention, designed based on focus group discussions, included four group sessions, two with spousal participation and all with on-site childcare. Web/telephone-based support was provided between sessions. We computed mean percentage change from baseline (95\% confidence intervals, Cl) for anthropometric measures, glucose tolerance (75 g Oral glucose tolerance test), insulin resistance/sensitivity, blood pressure, physical activity, dietary intake, and other cardiometabolic risk factors.

Results: Among the 36 enrolled, 27 completed final evaluations. Most attended $\geq 3$ sessions (74\%), used on-site childcare (88\%), and logged onto the website (85\%). Steps/day (733 steps, $95 \% \mathrm{Cl} 85,1391)$ and fruit/vegetable intake (1.5 servings/day, $95 \% \mathrm{Cl} 0.3,2.8)$ increased. Proportions decreased for convenience meal consumption $(-30 \%$, $95 \% \mathrm{Cl}-50,-9)$ and eating out $(-22 \%, 95 \% \mathrm{Cl}-44,-0) \geq 3$ times/month. Body mass index and body composition were unchanged. Fasting $(-4.9 \%, 95 \% \mathrm{Cl}-9.5,-0.3)$ and 2 -hour postchallenge $(-8.0 \%, 95 \% \mathrm{Cl}-15.6,-0.5)$ glucose declined. Insulin sensitivity increased (ISI 0,120 23.7\%, 95\% CI 9.1, 38.4; Matsuda index 37.5\%, 95\% CI 3.5, 72.4). Insulin resistance (HOMA-IR $-9.4 \%, 95 \% \mathrm{Cl}-18.6,-0.1)$ and systolic blood pressure $(-3.3 \%, 95 \% \mathrm{Cl}-5.8,-0.8)$ decreased.
\end{abstract}

Conclusions: A tailored group intervention appears to lead to improvements in health behaviours and cardiometabolic risk factors despite unchanged body mass index and body composition. This approach merits further study.

Clinical trial registration: ClinicalTrials.gov (NCT01814995).

Keywords: Gestational diabetes, Type 2 diabetes, Prevention, Insulin resistance, Diet, Exercise, Childcare, Spouse participation

\footnotetext{
* Correspondence: Kaberi.dasgupta@mcgill.ca

${ }^{\dagger}$ Equal contributors

Division of Clinical Epidemiology, Department of Medicine, McGill University

Health Centre, 687 Pine Avenue West, H3A 1A1, Montreal, Quebec, Canada
} 


\section{Introduction}

Women with a gestational diabetes (GDM) history have a greater than seven-fold risk increase for type 2 diabetes $[1,2]$ and increased cardiovascular disease risk $[3,4]$, compared to women without glucose elevations in pregnancy. The American Diabetes Prevention Program trial (DPP) [5] demonstrated that in prediabetes, an individualised eating and physical activity behaviour change program led to a greater than $50 \%$ reduction in type 2 diabetes incidence. Further, impact was specifically confirmed in women within an average of 12 years of first GDM pregnancy. However, given that the period of highest diabetes incidence is within 5 years of a GDM pregnancy [6], the DPP intervention was arguably "late." Engaging women earlier could not only prevent more cases of type 2 diabetes but also reduce the risk of recurrent GDM [7]. Notably, subsequent pregnancies without GDM are an indicator of decreased risk of type 2 diabetes development later in life [8].

Unfortunately, trials within 5 years of a GDM pregnancy have met with limited success. Interventions have mainly been at the individual level, including dietary and physical activity counselling and support. These have been delivered through face-to-face consultations with additional phone/text/email support [9-12] or without face-to-face contact, relying exclusively on phone calls and written material [13] or web-based programs [14]. A single study examined a group-based approach consisting of weekly physical activity sessions [15]. In all cases, impact on weight was limited [10-14]. When assessed, no improvements in fasting $[10,12,14,15]$ or 2 -hour post challenge glucose $[12,14,15]$ have been observed. Further, participation appears to be challenging $[15,16]$, largely because of work and family-related responsibilities. There is a need for the development and testing of alternate strategies, as well as assessment of impact on a greater variety of cardiometabolic risk factors, to comprehensively capture possible benefits.

As previously reported, we conducted focus group discussions with women within 5 years of a GDM pregnancy, seeking their input on the design of a realistic intervention strategy. Our analyses signalled a need for group-based face-to-face interactions with peers and professionals [17]. However, to facilitate attendance, on-site childcare was viewed to be important. Phone, web-based, and text support were considered adjunctive. Spousal involvement was deemed critical to allow health behavioural change at home. We designed an intervention that incorporated these elements. We assessed its impact through the MoMM pilot study, evaluating not only changes in body weight but in insulin resistance, blood pressure, lipid profile, eating behaviours and daily step counts, as reported herein.

\section{Subjects and methods}

MoMM was a single-arm pilot interventional study (ClinicalTrials.gov: NCT01814995) examining pre- to post intervention changes. This design permits each woman to act as her own control [18]. The protocol was approved by McGill University's Faculty of Medicine Institutional Review Board and all participating institutions (McGill University Health Centre, Sir Mortimer General Jewish General Hospital, and Concordia University). Participants provided written informed consent. The acronym MoMM originally stood for Combining MOtivational Support, Meal Preparation Training, and a Tapering Course of Meal Replacements To Achieve Vascular Risk Reduction in Women with a Gestational Diabetes History; however, focus group discussion indicated that women preferred not to use meal replacements. The title was therefore changed to Mindful mOvement, Mindful eating, Mindful living.

\section{Eligibility criteria and recruitment}

Inclusion criteria were GDM pregnancy within the prior 5 years and $\mathrm{BMI} \geq 24 \mathrm{~kg} / \mathrm{m}^{2}$. Exclusion criteria were other forms of diabetes, current use of antihyperglycemic medication, pregnancy or attempting to become pregnant, current smoking, or co-morbid conditions or medications that could impact weight. Recruitment occurred through the GDM clinics of participating institutions. Strategies included invitation letters from the treating physicians with follow-up telephone calls by study personnel (Additional file 1: Figure S1).

\section{Intervention}

There were four monthly group-based sessions, each 4 hours in duration and held on a weekend day morning at Concordia University's PERFORM centre (http:// performcentre.concordia.ca/en/), a research and teaching facility equipped with a kitchen (four work stations) and an exercise area. Partners were invited to sessions 2 and 4. Experienced childcare providers from a nearby daycare were hired to supervise the children on-site during sessions.

Sessions began with a one-hour period with an exercise physiologist who discussed the importance of physical activity and strategies for its integration into the daily routine. Participants were provided with pedometers and resistance exercise bands. At the first session, they did a practice walk with the pedometer and were instructed in its use. They were encouraged to monitor their daily steps, aiming to progressively achieve/surpass 10,000 steps/day [19]. They practiced floor exercises, with and without the resistance bands, under supervision.

Over the following three hours, a registered dietitian discussed eating behaviour and nutrition and supervised participants in the preparation of a balanced meal. They 
were encouraged to eat at regular intervals to avoid strong 'hunger' sensations that could provoke overeating; to plan intake; to have healthy snacks visible at home and work (e.g., eat a fruit first); to take the time to savour meals and snacks with minimal distractions to help recognition of satiety signals; and to try to eat as a family. There was an emphasis on appropriate food group proportions demonstrated using the Canadian Diabetes Association's Balanced Plate Method (e.g., 1/2 plate vegetables, $1 / 4$ plate cereals and grains, $1 / 4$ plate protein) and the Handy Portion Guide [20]. This was operationalized when participants and their families served themselves the meal, under the dietitian's supervision. On a separate occasion, participants had an opportunity to meet with a nutrition student for a grocery store tour, to discuss produce selection.

The study-specific website included information on GDM and type 2 diabetes, recipe ideas, stress management tips, and links to tools for the tracking of dietary intake (www.eaTracker.ca) and physical activity (www. stepscount.com). A discussion forum was available to address barriers to achieving healthier choices. Participants were also contacted individually by telephone two to three times per month by study personnel, to assess progress and to respond to any questions.

\section{Outcomes}

Demographic information, family history, and past medical history were queried at baseline. All other assessments were conducted both at baseline and post intervention at the McGill Nutrition and Performance Laboratory, following an overnight fast.

\section{Anthropometric measures and body composition}

Weight to the nearest 0.1 kilogram (Digital Physician Scales, model 140-10-6 by Rice Lake Weighing Systems, light clothing, shoes removed) and height to the nearest 0.1 centimeter (Stadiometer PE-WM-60-76-BRG2, Perspective Enterprises) were assessed and BMI calculated. Waist circumference was measured midway between the iliac crest and the lower rib margin. Dual-Energy X-ray absorptiometry (DXA; GE Lunar Prodigy Advance) was performed to estimate the percentage of total body fat.

\section{Oral glucose tolerance test and insulin resistance}

Plasma glucose (glucose oxidase method) and insulin (ELISA method) were measured on blood samples drawn in the fasting state and at 60 and 120 minutes following ingestion of a $75 \mathrm{~g}$ glucose solution. The Homeostatic Model Assessment Insulin resistance (HOMA-IR) [21], Matsuda index [22,23], and insulin sensitivity index (ISI 0, 120) [24] were computed. Other serum markers. Lipid parameters (Total-cholesterol, HDL, Triglycerides) were measured on fasting blood samples (Piccolo xpress technic) and LDL was calculated. Adiponectin and leptin concentrations were assayed (Human Total Adiponectin/ Acrp30 Quantikine ELISA Kit, cat. DRP300, R\&D systems; Human Leptin Quantikine ELISA Kit, cat. DLP00, R\&D systems). Blood pressure. Blood pressure was assessed in a seated position with the arm supported following a 5 -minute rest period. Six measurements at 1-minute intervals were recorded (Mindray Accutor $-\mathrm{V}$ Vital Signs Monitor). The last 5 systolic (SBP) and diastolic blood pressure (DBP) measurements were separately averaged.

\section{Dietary intake and eating behaviour}

A registered dietitian conducted 24-hour dietary recalls to determine number of daily servings by food group (Canada Food Guide) [25]. Participants were asked about the frequency of eating pre-prepared convenience foods or restaurant meals [26]. Perceived ability to cook from basic ingredients was assessed (7-point scale) [27]. Other self-administered questionnaires included the Weight Efficacy Lifestyle (WEL) [28] which assesses eating-related self control (scores 1-9) and the Mindful Eating Questionnaire (MEQ) [29] (scores 1 to 4). The Weight Stages of Change-Short Form was also administered [30].

\section{Physical activity behaviour}

Daily step counts were measured using Yamax SW-200 (Yamasa Tokei Keiki Co., Ltd, Tokyo, Japan) pedometers over 7 days [31]. Participants also wore a multi-axial accelerometer (ActiGraph GT3X, Actigraph LLC., Pensacola, FL). To be included in the analysis, participants had to have worn the accelerometer for at least 10 hours per day for a minimum of 3 days. Other. Participants completed the Hospital Anxiety and Depression Scale (HADS, 14 items) [32]. At the time of the final evaluation, participants completed a questionnaire querying utility of the sessions, with specific questions about the cooking and physical activity components, the importance of on-site childcare, reasons for partner's attendance/nonattendance, utility of the eaTracker tool, pedometer, pedometer step count tracker tool, and MoMM website, as well as suggestions about ways to improve the website.

\section{Statistical analysis}

Descriptive statistics are presented as means and standard deviations (SD), median and interquartile range (IQR), or proportions, as appropriate. Mean changes and $95 \%$ confidence intervals were calculated in unit and percentage change from baseline for clinical and behavioural parameters. 


\section{Results}

Thirty-six women were recruited. Among these, 27 (75.0\%) completed baseline and final assessments. Among the 9 women that withdrew, 5 did not attend any group-sessions (new pregnancy, 2; divorce or death in family, 2; unspecified, 1) and 4 attended at least one (time pressure, 2; feeling depressed, 1; divorce, 1). Those who completed both assessments were, on average, approaching their middle years (mean age 40 years, SD 5) and educated beyond high school (88.9\%). More than half (63.0\%) were Europid, most lived with their partner (92.6\%), had an average of two children, and worked outside the home (74.1\%). Questionnaire data indicated that 5 (18.5\%) had elevated anxiety levels and one had depressed mood (3.7\%). Roughly half reported limited social media use (never, 18.5\%; monthly, 33.3\%). At baseline, most were in an action $(44.4 \%)$ or maintenance $(18.5 \%)$ stage for weight change.

Four women $(14.8 \%)$ were included in the study although their BMIs were $<24 \mathrm{~kg} / \mathrm{m}^{2}$, (i.e., did not meet eligibility criteria). We opted to include them because of recruitment challenges. Three $(11.1 \%)$ more had a BMI between 24 and $25 \mathrm{~kg} / \mathrm{m}^{2}, 10(37.0 \%)$ were overweight $\left(25 \leq \mathrm{BMI}<30 \mathrm{~kg} / \mathrm{m}^{2}\right)$ and 10 (37.0\%) were obese $\left(B M I \geq 30 \mathrm{~kg} / \mathrm{m}^{2}\right)$. Eleven $(37.0 \%)$ met criteria for dysglycemia (3 impaired fasting glucose alone, 1 impaired glucose tolerance alone, 6 impaired fasting glucose and impaired glucose tolerance, 1 type 2 diabetes). We opted to retain the individual with type 2 diabetes but performed a sensitivity analysis excluding this individual.

Roughly one third (33.3\%, Table 1) who completed baseline and final assessments attended all in-person sessions. Approximately half (48.1\%) missed a single session. Most used the free on-site childcare $(88.9 \%)$ at all sessions that they attended. Among the 25 (92.6\%) who lived with a partner, $10(40.0 \%)$ had a partner who attended at least one session. Almost all participants (85.2\%) visited the MoMM website. Half (51.9\%) used the on-line step count-tracking tool and logged onto the eaTracker tool (59.3\%). Participants emailed the staffcontact a median of 5.5 times (IQR 5.5-15.5) over the course of the study.

\section{Dietary intake, eating behaviours, and physical activity}

Most $(n=19 ; 73 \%)$ perceived themselves to be at least a competent cook at baseline. This increased to $77.8 \%$ $(n=21)$ post intervention. Fruit and vegetable consumption increased from 3.7 (SD 2.7) servings/day at baseline to 5.2 (SD 3.4) at the final evaluation (mean increase: 1.5 servings/day, 95\% CI 0.3, 2.8) (Figure 1). The proportion of participants consuming pre-prepared convenience meals more than three times per month declined from $48 \%$ at baseline to $19 \%$ post intervention $(-30 \%, 95 \%$
Table 1 Participation during the 13-week intervention

\begin{tabular}{|c|c|}
\hline \multicolumn{2}{|l|}{ Intervention components } \\
\hline \multicolumn{2}{|l|}{ Sessions attendance } \\
\hline Four sessions; n (\%) & $9(33.3 \%)$ \\
\hline Three sessions; n (\%) & $11(40.7 \%)$ \\
\hline Two sessions; $n(\%)^{*}$ & $6(22.2 \%)$ \\
\hline \multicolumn{2}{|l|}{ Child-care use } \\
\hline Ever use; n (\%) & $24(88.9 \%)$ \\
\hline $\begin{array}{l}\text { Sessions used among those with ever use } \\
\text { (\% of attended sessions) }\end{array}$ & $100 \%$ \\
\hline \multicolumn{2}{|l|}{ Partners' attendance $^{\dagger}$} \\
\hline One session; $\mathrm{n}(\%)$ & $7(28.0 \%)$ \\
\hline Two sessions; n (\%) & $3(12.0 \%)$ \\
\hline \multicolumn{2}{|l|}{ Grocery store visit } \\
\hline Signed up to participate; $\mathrm{n}(\%)$ & $7(25.9 \%)$ \\
\hline Participated; n (\%) & $2(7.4 \%)$ \\
\hline \multicolumn{2}{|l|}{ Web-use } \\
\hline Visited website; n (\%) & $23(85.2 \%)$ \\
\hline Visits to website, median (IQR) & $21(8.4-44.5)$ \\
\hline Use of step count log; n (\%) & $14(51.9 \%)$ \\
\hline Use of eaTracker; n (\%) & $16(59.3 \%)$ \\
\hline Visited web-forum; n (\%) & $13(48.1 \%)$ \\
\hline Posted comments on web-forum; $\mathrm{n}(\%)$ & $2(7.4 \%)$ \\
\hline \multicolumn{2}{|l|}{ Contact by Participants with MoMM coordinator } \\
\hline Contacted by email; n (\%) & $25(92.6 \%)$ \\
\hline Emails sent by participants; median (IQR) & $5.5(5.5-15.5)$ \\
\hline Contacted by text messages; $\mathrm{n}(\%)$ & $4(3.7 \%)$ \\
\hline
\end{tabular}

*Two women were recruited after the first group session; they participated in two out of three sessions.

${ }^{\dagger}$ Two women were single parents; Maximum of partners that could attend $=25$.

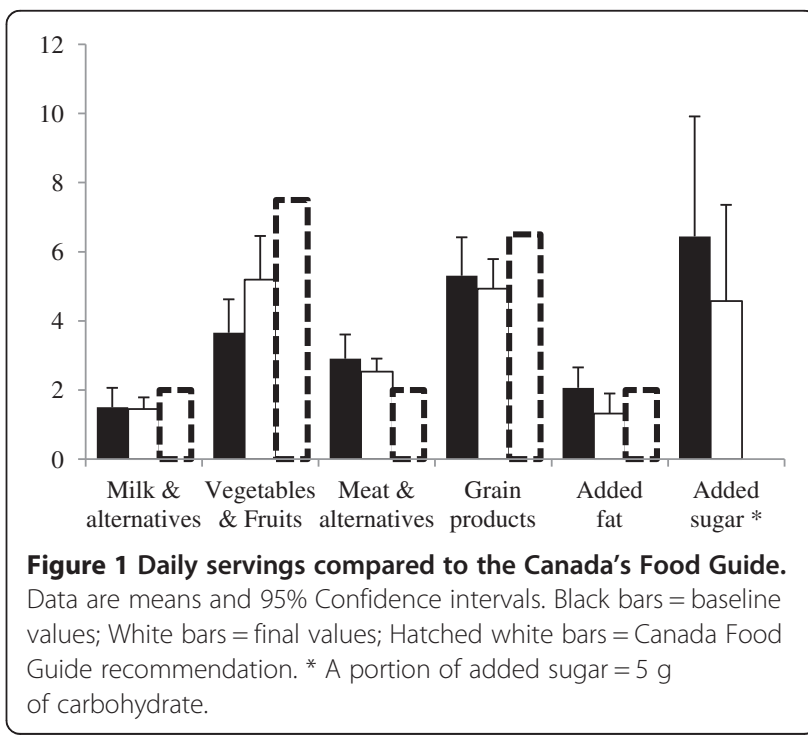


CI $-50,-9)$. The proportion reporting eating out more than three times per month decreased from 50\% at baseline to $30 \%$ post intervention $(-22 \%, 95 \%$ CI $-44,0)$. There were no important changes in the WEL or MEQ scores. There were no important changes in accelerometerbased measures of physical activity, but only 20 participants wore their accelerometer the required $\geq 10$ hours per day for at least during 3 days. In contrast, pedometer data indicated that by the end of the program, women were completing an additional 733 steps/day (95\% CI 85,1391 ) reaching a mean of 7,762 (SD 2368). This change corresponds to an $18.8 \%$ improvement (95\% CI $6.6,20.9)$.

\section{Weight and body composition}

The mean weight loss (Table 2) was $-0.2 \mathrm{~kg}$ of total body weight $(95 \% \mathrm{CI}-1.0,0.5)$ and $-0.1 \mathrm{~kg}$ of total fat mass (95\% CI -0.8, 0.5). Glucose tolerance. There were mean reductions in FPG $(-0.3 \mathrm{mmol} / \mathrm{L}, 95 \% \mathrm{CI}-0.6,-0.0)$ and in 2hPG (mean $-0.7 \mathrm{mmol} / \mathrm{L}, 95 \% \mathrm{CI}-1.4,-0.1$ ) values (Table 2; Figure 2). The participant with a new diagnosis of type 2 diabetes had reductions in both FPG, from 8.5 to $5.2 \mathrm{mmol} / \mathrm{L}$, and in $2 \mathrm{hPG}$, from 16.5 to $11.2 \mathrm{mmol} / \mathrm{L}$, without institution of any antihyperglycemic medication.
Measures of insulin resistance and sensitivity. Insulin resistance, as captured by HOMA-IR, decreased by a mean of $-0.2(95 \%$ CI $-0.5,0.0)$, nearly a $10 \%$ reduction $(-9.4 \%$, $95 \%$ CI $-18.6,-0.1)$. Correspondingly, there were increases in both measures of insulin sensitivity. The Matsuda index increased by a mean of 1.5 (95\% CI -0.3 , $3.3)$, a $37.9 \%$ increase $(95 \% \mathrm{CI} 3.5,72.4)$. The $\mathrm{ISI}_{0,120}$ increased by a mean of $13.1 \mathrm{mg} \times \mathrm{L}^{2} / \mathrm{mmol} \times \mu \mathrm{U} \times \min (95 \%$ CI 5.0, 21.2), a $23.7 \%$ increase (95\% CI 9.1, 38.4). Women in all BMI categories demonstrated a similar trend for glucose tolerance change (Additional file 1: Table S1). In a sensitivity analysis excluding the individual with type 2 diabetes retained, the point estimates were unchanged but the confidence intervals slightly widened (e.g. 2hPG went from $-8.0 \%$ [95\% CI $-15.6,-0.5$ ] to $-7.6 \%$ [95\% CI -14.6 , 0.5] and $\mathrm{ISI}_{0,120}$ from $23.7 \%$ [95\% CI 9.1, 38.4] to $22.4 \%$ [95\% CI 7.4, 37.4)]. Blood pressure. There were reductions in both SBP $(-4.2 \mathrm{mmHg}, 95 \% \mathrm{CI}-7.4,-1.0)$ and in DBP (-3.1 mmHg, 95\% CI -5.3, -0.9). Lipid profile. Triglycerides were also lower post intervention $(-0.4 \mathrm{mmol} / \mathrm{L}, 95 \%$ CI $-0.4,-0.1$ ), but other lipid parameters (HDL, LDL and Total-Cholesterol) remained unchanged. Adiponectin and leptin. Changes for adiponectin and leptin values were inconclusive with large confidence intervals.

Table 2 Changes in cardiometabolic measures

\begin{tabular}{|c|c|c|c|c|}
\hline & $\begin{array}{l}\text { Baseline all }(n=36) \text {, } \\
\text { mean }(S D)\end{array}$ & $\begin{array}{l}\text { Baseline completed }(n=27) \text {, } \\
\text { mean (SD) }\end{array}$ & $\begin{array}{l}\text { Final completed }(n=27) \text {, } \\
\text { mean }(S D)\end{array}$ & $\begin{array}{l}\text { Change from baseline, } \\
\text { mean }[95 \% \mathrm{Cl}]\end{array}$ \\
\hline Weight, kg & $77.1(19.0)$ & $76.4(17.1)$ & $76.2(17.2)$ & $-0.3 \%[-1.3,0.7]$ \\
\hline Body mass index, $\mathrm{kg} / \mathrm{m}^{2}$ & $29.3(7.0)$ & $29.1(6.7)$ & $29.0(6.8)$ & $-0.3 \%[-1.3,0.7]$ \\
\hline Waist circumference, $\mathrm{cm}$ & $92.7(14.6)$ & $91.8(13.7)$ & $90.8(13.6)$ & $-0.9 \%[-2.6,0.7]$ \\
\hline Fat mass, \%* & $40.7(7.1)$ & $41.7(6.7)$ & $41.5(7.0)$ & $-0.5 \%[-2.0,1.1]$ \\
\hline Systolic blood pressure, mm Hg & $119.6(11.2)$ & $120.0(11.2)$ & $115.8(11.4)$ & $-3.3 \%[-5.8,-0.8]$ \\
\hline Diastolic blood pressure, $\mathrm{mm} \mathrm{Hg}$ & $70.4(6.7)$ & $71.3(6.9)$ & $68.2(8.4)$ & $-4.3 \%[-7.3,-1.3]$ \\
\hline Fasting plasma glucose, mmol/L & $5.7(0.8)$ & $5.8(0.8)$ & $5.5(0.9)$ & $-4.9 \%[-9.5,-0.3]$ \\
\hline 1-h plasma glucose, mmol/L & $9.5(2.9)$ & $9.8(3.1)$ & $9.1(3.6)$ & $-5.0 \%[-19.1,9.1]$ \\
\hline 2-h plasma glucose, $\mathrm{mmol} / \mathrm{L}^{\dagger}$ & $7.2(2.9)$ & $7.6(3.3)$ & $6.8(2.8)$ & $-8.0 \%[-15.6,-0.5]$ \\
\hline Fasting insulin, $\mu \mathrm{U} / \mathrm{mL}$ & $7.9(4.5)$ & $8.5(4.9)$ & $8.1(5.0)$ & $-5.3 \%[-13.3,2.7]$ \\
\hline 1-h insulin, $\mu \mathrm{U} / \mathrm{mL}^{*}$ & $88.7(80.0)$ & $101.7(88.8)$ & $82.5(46.3)$ & $-2.2 \%[-24.9,20.6]$ \\
\hline 2-h insulin, $\mu \mathrm{U} / \mathrm{mL}^{\dagger}$ & $63.5(65.0)$ & $75.7(72.7)$ & $55.0(50.2)$ & $-15.9 \%[-35.6,3.8]$ \\
\hline ISI $0,120, \mathrm{mg} \times \mathrm{L}^{2} / \mathrm{mmol} \times \mu \mathrm{U} \times \min ^{\dagger}$ & $56.6(26.3)$ & $59.3(31.9)$ & $72.3(41.4)$ & $23.7 \%[9.1,38.4]$ \\
\hline Matsuda Index ${ }^{\dagger}$ & $5.6(3.9)$ & $5.0(4.0)$ & $6.5(6.4)$ & $37.9 \%[3.5,72.4]$ \\
\hline HOMA-IR & $2.0(1.3)$ & $2.2(1.4)$ & $2.0(1.3)$ & $-9.4 \%[-18.6,-0.1]$ \\
\hline Total Cholesterol, mmol/L & $5.0(0.7)$ & $4.9(0.6)$ & $4.8(0.7)$ & $-1.9 \%[-4.9,1.1]$ \\
\hline HDL-cholesterol, mmol/L & $1.3(0.3)$ & $1.3(0.3)$ & $1.3(0.4)$ & $0.0 \%[-4.0,4.0]$ \\
\hline LDL-cholesterol, mmol/L & $3.0(0.6)$ & $2.9(0.6)$ & $2.9(0.5)$ & $2.1 \%[-2.4,6.7]$ \\
\hline Triglycerides, mmol/L & $1.4(0.8)$ & $1.5(0.9)$ & $1.30(0.7)$ & $-9.7 \%[-20.2,0.9]$ \\
\hline Adiponectin, $\mu \mathrm{g} / \mathrm{mL}$ & $6.8(4.4)$ & $6.6(4.0)$ & $6.7(4.0)$ & $2.2 \%[-3.7,8.1]$ \\
\hline Leptin, ng/mL & $25.2(16.7)$ & $23.6(13.8)$ & $26.2(17.5)$ & $11.4 \%[-1.8,24.6]$ \\
\hline
\end{tabular}

*Data available for 26 who completed baseline and final assessments.

${ }^{\dagger}$ Data available for 25 who completed baseline and final assessments. 


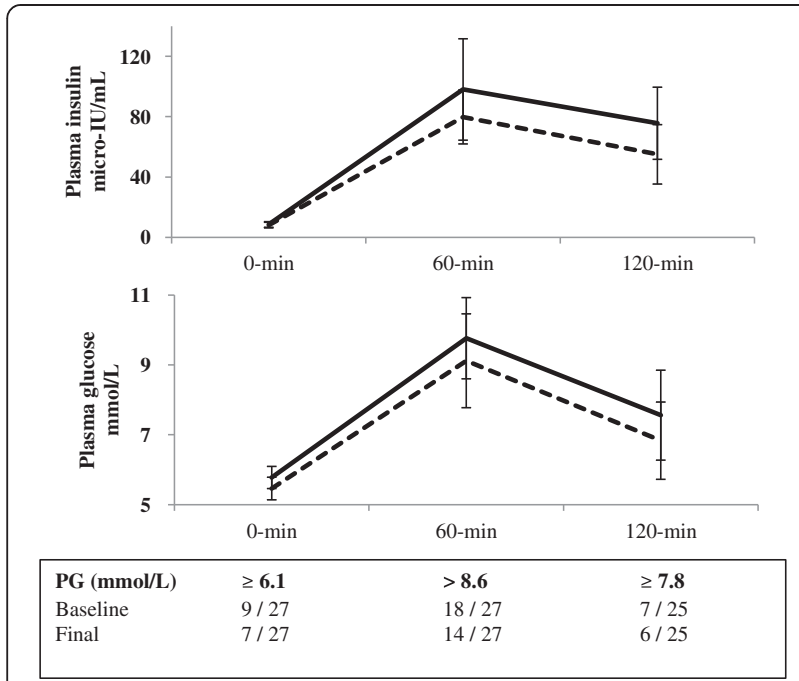

Figure 2 Plasma glucose and plasma insulin during the oral glucose tolerance tests. Black line $=$ baseline; Hatched line $=$ final. PG = Plasma glucose. Data are means and 95\% confidence intervals.

\section{Participants' impressions of the program}

Twenty-three participants completed the post intervention questionnaire related to impressions/opinions related to the intervention strategy. There was strong indication that participants perceived sessions as useful in promoting eating behaviour change (92\%). The incorporation of 'hands-on' cooking was deemed important (88\%) and indication that the physical activity education sessions helped increase activity levels (92\%). A large proportion indicated that the pedometer was a useful tool (92\%). Many noted that the availability of on-site childcare facilitated session attendance (79\%). In terms of partner attendance, 9\% did not have a partner and 70\% indicated that their partner could not attend (35\%- no time; 35\%- did not want to attend).

In terms of on-line tools, over half (56\%) indicated that the MoMM website was useful to them, $44 \%$ reported the on-line step count log to be helpful, and 40\% appreciated the eaTracker tool. Conversely, an important proportion reported never logging on to these sites/tools (32\% for MoMM website, $40 \%$ for on-line step count $\log , 36 \%$ for eaTracker). Some individuals did log on but did not perceive the tools to be useful (12\% for MoMM website, $16 \%$ for on-line step count log, $24 \%$ for eaTracker); these individuals either experienced frustrations/challenges with the sites (amount of information, errors, juggling passwords- four responses), preferred to use paper and pencil tracking (three responses), or may have preferred a Facebook page (one comment).

\section{Discussion}

Among women within 5 years of a GDM pregnancy who participated in a 13-week tailored intervention (i.e., 4 group sessions, partners invited to two, on-site childcare, meal preparation, pedometers and floor exercises), attendance at sessions was high, the childcare service and website were used, and there was some spousal participation. Self-reported eating control was not enhanced and there were no changes in BMI or body composition. However, there were important increases in fruit and vegetable intake and consumption of both convenience meals and eating out declined. Step counts also increased. There were reductions in both fasting and 2-hour postchallenge glucose and improvements in all measures of insulin resistance and sensitivity. There was also lowering of both systolic and diastolic blood pressure and triglycerides. On balance, the tailored intervention demonstrated both behavioural and biological impact and thus merits further study and development.

Less than a fifth of the participants missed 2 or more of the 4 sessions. On-site childcare may have been a key facilitating factor as evidenced by high use, with almost $90 \%$ of the women using it at every session they attended. Further, monthly sessions may have also enhanced attendance, being realistically aligned with time availability. Indeed, in a comprehensive lifestyle change study post pregnancy in a non GDM population, participants were able to attend only 4 of 10 scheduled sessions [16]. Higher attendance had been observed in studies with phone-based or at home sessions, and if sessions are scheduled at the same time of routine medical followup [33,34]. For example, among women with GDM who were recruited during pregnancy, 79\% completed, during pregnancy, $\geq 2$ out of 3 sessions (i.e., 1 in-person and 2 telephone counselling calls) and, in the postpartum period, they participated in an average of 9.4 sessions out of a maximum of 15 (i.e., a maximum of 2 in-persons and a maximum of 13 telephone counselling calls) [9]. We would note, however, that our participants expressed strong endorsement of in-person group sessions and had high levels of attendance.

In the focus group discussions that helped us to design the intervention [17], women expressed a need for spousal involvement. A need for spousal involvement to achieve changes in health behaviour has also emerged in other qualitative studies conducted among women with a GDM history $[35,36]$. Spousal participation was not a component of previous intervention studies [9-13,15]. The attempt to involve spouses is a novel aspect of our intervention. While we did invite spouses to two of the four intervention sessions and there was some participation, a large proportion of spouses did not attend any sessions. Better engagement may further enhance health behaviour change. While time constraints are a real challenge, lack of interest could potentially be addressed with better knowledge about personal and familial diabetes risks related to eating and physical activity habits 
of the family. Our recent systematic review and metaanalysis [37] estimated that type 2 diabetes in one spouse is associated with a $26 \%$ increased risk for type 2 diabetes in the other; further, studies that performed blood tests systematically indicated a doubling of diabetes risk. The concept of shared diabetes risk may potentially be leveraged to increase engagement of spouses in diabetes prevention efforts.

Our post-intervention questionnaire related to impressions/opinions on the intervention strategy suggests a high level of endorsement for in-person, hands-on components, and pedometer use. The availability of on-site childcare was a clear facilitator. While a substantial proportion did use the on-line tools and website, this was much less than in-person session participation. This may not be surprising given that half of participants reported not using web-based media frequently (i.e., less than monthly) at baseline. Web-based tools appear to be underutilised by this group of adults. In a web-based pedometer intervention in women with a GDM history, Kim and colleagues [14] noted that only 3 out of 21 participants used the web forum and questions were only directed to the study staff. This is unfortunate given the low cost and convenience of web and text-based communications. Future studies may need to incorporate strategies to facilitate webbased communication and engagement. For example, study personnel may need to proactively encourage web-based discussion among participants.

The 1.5 servings/day increase in fruit and vegetable intake that we observed likely contributed to the cardiometabolic benefits realized (i.e., glucose, insulin resistance and sensitivity, triglycerides, blood pressure). In a cross-sectional study on 2,115 adults at risk for diabetes, a two-serving increase in daily fruit and vegetable consumption was associated with a $0.08 \mathrm{mmol} / \mathrm{L}$ reduction in FPG and $0.2 \mathrm{mmol} / \mathrm{L}$ reduction in $2 \mathrm{hPG}$ [38]. In a pooled analysis of three prospective cohort studies, fruit consumption was associated with a lower risk of type 2 diabetes (Hazard Ratio 0.98, 95\% CI 0.97, 0.99 for three servings/week increment of total whole fruit consumption) [39]. Consistent with the protective effects of fruits and vegetables, diabetes risk calculators, such as FINDRISC, include daily vegetables, fruits and berries consumption as a factor that protects against diabetes development [40]. Moreover, specifically among women, the European Prospective Investigation into Cancer and Nutrition study demonstrated that a 0.5 serving increase in daily intake of vegetables to be associated with 0.20 and $0.09 \mathrm{~mm} \mathrm{Hg}$ reductions in SBP and DBP, respectively [41]. As reviewed in a meta-analysis of randomised controlled trials, a $10 \mathrm{~mm} \mathrm{Hg}$ reduction in SBP or $5 \mathrm{~mm} \mathrm{Hg}$ reduction in DBP leads to a $22 \%$ reduction in coronary heart disease events and a $41 \%$ reduction in stroke [42]. Our participants achieved mean reductions of more than $4 \mathrm{~mm} \mathrm{Hg}$ in SBP and $3 \mathrm{~mm} \mathrm{Hg}$ in DBP, clinicallyimportant changes.

We observed a 733 steps/day increase, greater than that observed in a 12-week web-based pedometer program (mean 543, SD 2074) in women with a GDM history [14]. Among NAVIGATOR trial participants (Nateglinide and Valsartan in Impaired Glucose Tolerance Outcomes Research), both step counts at baseline and mean 6-year increases were associated with reductions in occurrence of cardiovascular events [43]. Our previous studies have demonstrated inverse relationships between blood pressure and step counts, particularly in women [44]. The increase in step counts thus likely also contributed to the cardiometabolic improvements we observed in the present study.

The mean improvements that we observed in FPG and 2hPG are at least as great as those observed in the Finnish Diabetes Prevention trial $(-0.3 \mathrm{mmol} / \mathrm{L}$ FPG; $-0.8 \mathrm{mmol} / \mathrm{L}$ 2hPG) [45]. Given that the Finnish Diabetes Prevention Trial, like the DPP, achieved major reductions in diabetes incidence through a lifestyle intervention, the comparability of the improvement in 2-hour post 75 g glucose challenge that we observed appears promising. Further, computations of insulin resistance and sensitivity derived from glucose and insulin measurements consistently demonstrated improvements (HOMA-IR, ISI $_{0,120}$, Matsuda index). Notably, higher insulin sensitivity estimated with the Matsuda index is associated with a decreased incidence of diabetes in high-risk populations [46].

We acknowledge several limitations. First, the primary outcome of our study was a change in weight but no important weight reduction was achieved. More emphasis on energy expenditure reduction may have led to greater weight changes, although adherence may have been challenging. Although our target population was overweight women within 5 years of a GDM pregnancy, some of the women enrolled had a normal BMI. Nonetheless, the BMI range of participants enrolled was more representative of women with GDM in general [47]. Weight reduction observed in overweight/obese women alone was also modest $-0.5 \%$ (95\% CI: $-1.7,0.8$ ), and other changes observed in normal-weight weight women were similar to those observed in the rest of the participants (Additional file 1: Table S1). Second, recruitment was challenging, as anticipated. We endeavoured to recruit women within 5 years of a GDM diagnosis. This is a period of high risk for conversion to type 2 diabetes [6]. While interventions even closer to the time of GDM diagnosis may have had even greater potential impact [6], it would have rendered recruitment more challenging. As reported in our previous focus group study, more than 1,000 invitation letters were sent to women with a prior GDM history. From this pool, we were able to enroll 29 in our focus group study and 28 in the intervention study, 
with the remainder recruited through telephone contact. The women enrolled may thus not be representative of all women within 5 years of a GDM pregnancy, although they may be representative of those willing to engage in prevention efforts. For capturing dietary intake, the use of a single 24-hour dietary intake recall limits the analysis of macronutrients and micro-nutrients intake (e.g., sodium) that may have impacted cardiometabolic risk factors but does provide an overall view of dietary intake. Accelerometry-based measurements were limited by low wear-time in this cohort. Finally, the lack of a control group is a limitation for this study. A large randomized controlled trial design would be better able to confirm that the cardiometabolic improvements and behavioural changes observed were attributable to the intervention. We plan to conduct such a study.

In summary, the MoMM pilot study indicates that, among women who enroll and participate, a group-based multimodal intervention with childcare support may be effective in lowering diabetes and vascular disease risk in women within 5 years of a GDM pregnancy. Building on such an approach has the potential to reduce diabetes risk and vascular complications- in mothers, fathers, and children.

\section{Additional file}

Additional file 1: Table S1. Baseline values and percentage of changes from baseline by baseline weight category. Figure S1. Recruitment's flow chart.

\begin{abstract}
Abbreviations
2hPG: 2 hour plasma glucose; DBP: Diastolic blood pressure; DPP: Diabetes prevention program; FPG: Fasting plasma glucose; GDM: Gestational diabetes; HADS: Hospital anxiety and depression scale; IQR: Interquartile range; MEQ: Mindful eating questionnaire; SBP: Systolic blood pressure; SD: Standard deviations; WEL: Weight efficacy lifestyle.
\end{abstract}

\section{Competing interests}

The authors declare that they have no competing interests.

\section{Authors' contributions}

$A S B, L J, A L$, and $K D$ analyzed data. ASB and KD drafted the manuscript and $L J, A L, D D, S M, M H N$, and $R C$ provided important input and revisions. $K D$, $D D, S M$, and $L J$ designed the study. MHN was involved in design of the dietary intervention, $\mathrm{AL}$ and $\mathrm{RC}$ led recruitment and evaluations and supervised interventions. RC designed the study website in collaboration with $\mathrm{KD}$ and the MoMM intervention team, acknowledged above. All authors reviewed and approved the manuscript. The authors have no conflicts of interest. KD had primary responsibility for final content.

\section{Authors' information}

Anne-Sophie Brazeau and Aaron Leong are Shared $1^{\text {st }}$ author.

\section{Acknowledgments}

This study was funded through a grant awarded to KD by the Canadian Institutes of Health Research (CAI 117789). Funding was also provided through a grant awarded to KD by the Canadian Diabetes Association. KD holds the Fonds de recherche Santé du Québec-Société québécoise d'hypertension artérielle-Jacques de Champlain Award. AL is a Canadian Diabetes Association post-doctoral research fellow.
The MOMM group includes the following co-investigators who provided important comments during initial study development: Simon Bacon (Department of Exercise Sciences, Concordia University, Montreal, Canada), Stephen Stotland (Department of Psychology, McGill University, Montreal, Canada), V. Tony Chetty (Department of Pathology and Molecular Medicine, McMaster University, Hamilton, Ontario, Canada) and Réjeanne Gougeon (Department of Medicine, McGill University, Montreal, Canada). Collaborators Natasha Garfield and Agnieszka Majdan (Department of Medicine, McGill University, Montreal, Canada) provided critical support for recruitment. Marie-Eve Robillard (Research Assistant) was involved with baseline and final assessments.

The MoMM intervention team was based at the PERFORM centre and included Thea Demmers (Registered Dietitian; PERFORM Centre) who designed the eating behaviour/ nutrition components of the intervention sessions in collaboration with KD and MHN and Nasim Sabri (Registered Dietitian; MSc Candidate, McGill University) who assisted Ms. Demmers during sessions and conducted the grocery store tour. Exercise physiologists Marion Lowe, Christina B. Weiss, and Kristin Martin (PERFORM Centre) designed and delivered the exercise component of the sessions in collaboration with $\mathrm{KD}$.

We thank the daycare Les Petits Anges de Wesley for their assistance with on-site childcare. Axel Bergman of PERFORM (Manager, Research Development) provided important logistical support.

Received: 4 March 2014 Accepted: 26 April 2014

Published: 30 June 2014

\section{References}

1. Bellamy L, Casas JP, Hingorani AD, Williams D: Type 2 diabetes mellitus after gestational diabetes: a systematic review and meta-analysis. Lancet 2009, 373:1773-1779.

2. Pirkola J, Pouta A, Bloigu A, Miettola S, Hartikainen AL, Jarvelin MR, Vaarasmaki M: Prepregnancy overweight and gestational diabetes as determinants of subsequent diabetes and hypertension after 20-year follow-up. J Clin Endocrinol Metab 2010, 95:772-778.

3. Retnakaran R, Shah BR: Mild glucose intolerance in pregnancy and risk of cardiovascular disease: a population-based cohort study. CMAJ 2009, 181:371-376.

4. Freire CM, Barbosa FB, de Almeida MC, Miranda PA, Barbosa MM, Nogueira Al, Guimaraes MM, Nunes Mdo C, Ribeiro-Oliveira A Jr: Previous gestational diabetes is independently associated with increased carotid intima-media thickness, similarly to metabolic syndrome - a case control study. Cardiovasc Diabetol 2012, 11:59.

5. Ratner RE, Christophi CA, Metzger BE, Dabelea D, Bennett PH, Pi-Sunyer X, Fowler S, Kahn SE: Diabetes Prevention Program Research G: Prevention of diabetes in women with a history of gestational diabetes: effects of metformin and lifestyle interventions. J Clin Endocrinol Metab 2008, 93:4774-4779.

6. Kim C, Newton KM, Knopp RH: Gestational diabetes and the incidence of type 2 diabetes: a systematic review. Diabetes Care 2002, 25:1862-1868.

7. Kim C, Berger DK, Chamany S: Recurrence of gestational diabetes mellitus: a systematic review. Diabetes Care 2007, 30:1314-1319.

8. Retnakaran R, Austin PC, Shah BR: Effect of subsequent pregnancies on the risk of developing diabetes following a first pregnancy complicated by gestational diabetes: a population-based study. Diabet Med 2011, 28:287-292

9. Ferrara A, Hedderson MM, Albright CL, Ehrlich SF, Quesenberry CP Jr, Peng T, Feng J, Ching J, Crites Y: A pregnancy and postpartum lifestyle intervention in women with gestational diabetes mellitus reduces diabetes risk factors: a feasibility randomized control trial. Diabetes Care 2011, 34:1519-1525.

10. Mclntyre HD, Peacock A, Miller YD, Koh D, Marshall AL: Pilot study of an individualised early postpartum intervention to increase physical activity in women with previous gestational diabetes. Int J Endocrinol 2012, 2012:892019.

11. Cheung NW, Smith BJ, van der Ploeg HP, Cinnadaio N, Bauman A: A pilot structured behavioural intervention trial to increase physical activity among women with recent gestational diabetes. Diabetes Res Clin Pract 2011, 92:e27-e29.

12. Shyam S, Arshad F, Abdul Ghani R, Wahab NA, Safii NS, Nisak MY, Chinna K, Kamaruddin NA: Low glycaemic index diets improve glucose tolerance 
and body weight in women with previous history of gestational diabetes: a six months randomized trial. Nutrition Journal 2013, 12:68.

13. Reinhardt JA, van der Ploeg HP, Grzegrzulka R, Timperley JG: Implementing lifestyle change through phone-based motivational interviewing in rural-based women with previous gestational diabetes mellitus. Health Promot J Austr 2012, 23:5-9.

14. Kim C, Draska M, Hess ML, Wilson EJ, Richardson CR: A web-based pedometer programme in women with a recent history of gestational diabetes. Diabet Med 2012, 29:278-283.

15. Cheung NW, Smith BJ, Henriksen H, Tapsell LC, McLean M, Bauman A: A group-based healthy lifestyle program for women with previous gestational diabetes. Diabetes Res Clin Pract 2007, 77:333-334.

16. Ostbye T, Krause KM, Lovelady CA, Morey MC, Bastian LA, Peterson BL, Swamy GK, Brouwer RJ, McBride CM: Active Mothers Postpartum: a randomized controlled weight-loss intervention trial. Am J Prev Med 2009, 37:173-180

17. Dasgupta K, Da Costa D, Pillay S, De Civita M, Gougeon R, Leong A, Bacon S, Stotland S, Chetty VT, Garfield N, Majdan A, Meltzer S: Strategies to optimize participation in diabetes prevention programs following gestational diabetes: a focus group study. PLOS One 2013, 8:e67878.

18. Hulley SB, Cummings SR, Browner WS, Grady DG, Newman TB: Alternative trial designs and implementation issues. In Designing clinical research Third edition. Edited by Woleters K. Philadelphia: Woleters Kluwer Lippincott Williams \& Wilkins; 2007.

19. Tudor-Locke C, Craig CL, Brown WJ, Clemes SA, Cocker De K, Giles-Corti B, Hatano Y, Inoue S, Matsudo SM, Mutrie N, Oppert JM, Rowe DA, Schmidt MD, Schofield GM, Spence JC, Teixeira PJ, Tully MA, Blair SN: How many steps/day are enough? For adults. Int J Behav Nutr Phys Act 2011, 8:79.

20. Canadian Diabetes Association: Just the basics. Tips for healthy eating. 2013. http://guidelines.diabetes.ca/CDACPG/media/documents/patientresources/just-the-basics-healthy-eating.pdf. Accessed 2014-04-24.

21. Matthews DR, Hosker JP, Rudenski AS, Naylor BA, Treacher DF, Turner RC: Homeostasis model assessment: insulin resistance and beta-cell function from fasting plasma glucose and insulin concentrations in man. Diabetologia 1985, 28:412-419.

22. Matsuda M, DeFronzo RA: Insulin sensitivity indices obtained from ora glucose tolerance testing: comparison with the euglycemic insulin clamp. Diabetes Care 1999, 22:1462-1470.

23. DeFronzo RA, Matsuda M: Reduced time points to calculate the composite index. Diabetes Care 2010, 33:e93.

24. Gutt M, Davis CL, Spitzer SB, Llabre MM, Kumar M, Czarnecki EM, Schneiderman N, Skyler JS, Marks JB: Validation of the insulin sensitivity index $(\mathrm{ISI}(0,120))$ : comparison with other measures. Diabetes Res Clin Pract 2000, 47:177-184.

25. Health Canada: Eating Well with Canada's Food Guide. 2011. http://www. hc-sc.gc.ca/fn-an/alt_formats/hpfb-dgpsa/pdf/food-guide-aliment/ view_eatwell_vue_bienmang-eng.pdf. Accessed on 2014-04-24.

26. Dufour Bouchard A-A, Farah R, Gagnon H, Lachance B, Lesage D, Mongeau L, Pageau M: Vision de la saine alimentation. La direction des communications du ministère de la santé et des services sociaux du Québec. 2010. http://publications.msss.gouv.qc.ca/acrobat/f/documentation/2009/09-289-10F. pdf. Accessed on 2014-04-24.

27. Beardsworth A, Bryman A, Keil T, Goode J, Haslam C, Lancashire E: Women, men and food: the significance of gender for nutritional attitudes and choices. British Food Journal 2002, 104:470-491.

28. Clark MM, Abrams DB, Niaura RS, Eaton CA, Rossi JS: Self-efficacy in weight management. J Consult Clin Psychol 1991, 59:739-744.

29. Framson C, Kristal AR, Schenk JM, Littman AJ, Zeliadt S, Benitez D: Development and validation of the mindful eating questionnaire. J Am Diet Assoc 2009, 109:1439-1444

30. O'Connell D, Velicer WF: A decisional balance measure and the stages of change model for weight loss. Int J Addict 1988, 23:729-750.

31. Crouter SE, Schneider PL, Karabulut M, Bassett DR Jr: Validity of 10 electronic pedometers for measuring steps, distance, and energy cost. Med Sci Sports Exerc 2003, 35:1455-1460.

32. Bjelland I, Dahl AA, Haug TT, Neckelmann D: The validity of the hospital anxiety and depression scale: an updated literature review. J Psychosom Res 2002, 52:69-77.

33. Craigie AM, Macleod M, Barton KL, Treweek S, Anderson AS, WeighWell T: Supporting postpartum weight loss in women living in deprived communities: design implications for a randomised control trial. Eur $J$ Clin Nutr 2011, 65:952-958.

34. Kinnunen TI, Pasanen M, Aittasalo M, Fogelholm M, Weiderpass E, Luoto R: Reducing postpartum weight retention-a pilot trial in primary health care. Nutr J 2007, 6:21.

35. Nicklas JM, Zera CA, Seely EW, Abdul-Rahim ZS, Rudloff ND, Levkoff SE: Identifying postpartum intervention approaches to prevent type 2 diabetes in women with a history of gestational diabetes. BMC Pregnancy Childbirth 2011, 11:23.

36. Lie ML, Hayes L, Lewis-Barned NJ, May C, White M, Bell R: Preventing type 2 diabetes after gestational diabetes: women's experiences and implications for diabetes prevention interventions. Diabet Med 2013, 30:986-993.

37. Leong A, Rahme E, Dasgupta K: Spousal diabetes as a diabetes risk factor: a systematic review and meta-analysis. BMC Med 2014, 12:12.

38. Carter P, Gray LJ, Talbot D, Morris DH, Khunti K, Davies MJ: Fruit and vegetable intake and the association with glucose parameters: a cross-sectional analysis of the let's prevent diabetes study. Eur J Clin Nutr 2013, 67:12-17.

39. Muraki I, Imamura F, Manson JE, Hu FB, Willett WC, van Dam RM, Sun Q: Fruit consumption and risk of type 2 diabetes: results from three prospective longitudinal cohort studies. BMJ 2013, 347:f5001.

40. Lindstrom J, Tuomilehto J: The diabetes risk score: a practical tool to predict type 2 diabetes risk. Diabetes Care 2003, 26:725-731.

41. Masala G, Bendinelli B, Versari D, Saieva C, Ceroti M, Santagiuliana F, Caini S, Salvini S, Sera F, Taddei S, Ghiadoni L, Palli D: Anthropometric and dietary determinants of blood pressure in over 7000 Mediterranean women: the European Prospective Investigation into Cancer and Nutrition-Florence cohort. J Hypertens 2008, 26:2112-2120.

42. Law MR, Morris JK, Wald NJ: Use of blood pressure lowering drugs in the prevention of cardiovascular disease: meta-analysis of 147 randomised trials in the context of expectations from prospective epidemiological studies. BMJ 2009, 338:b1665.

43. Yates T, Haffner SM, Schulte PJ, Thomas L, Huffman KM, Bales CW, Califf RM, Holman RR, McMurray JJ, Bethel MA, Tuomilehto J, Davies MJ, Kraus WE: Association between change in daily ambulatory activity and cardiovascular events in people with impaired glucose tolerance (NAVIGATOR trial): a cohort analysis. Lancet 2014, 383:1059-1066.

44. Manjoo P, Joseph L, Pilote L, Dasgupta K: Sex differences in step count-blood pressure association: a preliminary study in type 2 diabetes. PLoS One 2010, 5:e14086.

45. Tuomilehto J, Lindstrom J, Eriksson JG, Valle TT, Hamalainen $H$, llanne-Parikka P, Keinanen-Kiukaanniemi S, Laakso M, Louheranta A, Rastas M, Salminen V, Uusitupa M, Finnish Diabetes Prevention Study G: Prevention of type 2 diabetes mellitus by changes in lifestyle among subjects with impaired glucose tolerance. N Engl J Med 2001, 344:1343-1350.

46. de Mello VD, Lindstrom J, Eriksson J, llanne-Parikka P, KeinanenKiukaanniemi S, Sundvall J, Laakso M, Tuomilehto J, Uusitupa M: Insulin secretion and its determinants in the progression of impaired glucose tolerance to type 2 diabetes in impaired glucose-tolerant individuals: the finnish diabetes prevention study. Diabetes Care 2012, 35:211-217.

47. Edwards M, Meltzer S, Rahme E, Dasgupta K: Predictors of postpartum lipid abnormalities in women with gestational diabetes. Can Diabetes $J 2012$, 36:305-309.

doi:10.1186/1475-2840-13-104

Cite this article as: Brazeau et al:: Group-based activities with on-site childcare and online support improve glucose tolerance in women within 5 years of gestational diabetes pregnancy. Cardiovascular Diabetology 2014 13:104. 